University of Nebraska - Lincoln

DigitalCommons@University of Nebraska - Lincoln

Agronomy \& Horticulture - Faculty Publications

Agronomy and Horticulture Department

3-29-2003

\title{
An evaluation of four crop : weed competition models using a common data set
}

\author{
W. Deen \\ University of Guelph \\ R. Cousens \\ University of Melbourne \\ J. Warringa \\ University of Melbourne \\ L. Bastiaans \\ Wageningen Agricultural University \\ P. Carberrys \\ Agricultural Production Systems Research Unit, CSIRO Tropical Agriculture, PO Box 102, Toowoomba, \\ Queensland 4350, Australia
}

See next page for additional authors

Follow this and additional works at: https://digitalcommons.unl.edu/agronomyfacpub

Part of the Plant Sciences Commons

Deen, W.; Cousens, R.; Warringa, J.; Bastiaans, L.; Carberrys, P.; Rebel, K.; Riha, S.; Murphy, C.; Benjamin, L. R.; Cloughley, C.; Cussans, J.; Forcella, F.; Hunt, T.; Jamieson, P.; Lindquist, John; and Wangs, E., "An evaluation of four crop : weed competition models using a common data set" (2003). Agronomy \& Horticulture -- Faculty Publications. 125.

https://digitalcommons.unl.edu/agronomyfacpub/125

This Article is brought to you for free and open access by the Agronomy and Horticulture Department at DigitalCommons@University of Nebraska - Lincoln. It has been accepted for inclusion in Agronomy \& Horticulture -Faculty Publications by an authorized administrator of DigitalCommons@University of Nebraska - Lincoln. 


\section{Authors}

W. Deen, R. Cousens, J. Warringa, L. Bastiaans, P. Carberrys, K. Rebel, S. Riha, C. Murphy, L. R. Benjamin, C. Cloughley, J. Cussans, F. Forcella, T. Hunt, P. Jamieson, John Lindquist, and E. Wangs 


\title{
An evaluation of four crop : weed competition models using a common data set
}

\author{
W DEEN*, R COUSENS $\dagger, \mathrm{J}$ WARRINGA $\dagger$, L BASTIAANS $\dagger$, P CARBERRY§,

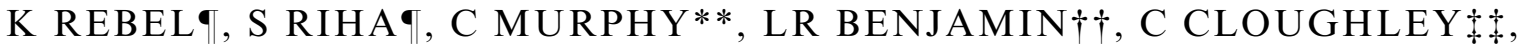 \\ J CUSSANS $\dagger \dagger$, F FORCELLA $\S, T$. HUNT*, P JAMIESON††, J LINDQUIST $\uparrow \&$ \\ E WANG§ \\ * Plant Agriculture Department, University of Guelph, Guelph, Ontario N1G 2W1, Canada, †Institute of Land and Food Resources, The \\ University of Melbourne, Victoria 3010, Australia, $\$$ Department of Theoretical Production Ecology, Wageningen Agricultural University, \\ Bornsesteeg 47, 6708 PD Wageningen, The Netherlands, §Agricultural Production Systems Research Unit, CSIRO Tropical Agriculture, PO \\ Box 102, Toowoomba, Queensland 4350, Australia, Department of Earth and Atmospheric Science, Cornell University, 1121 Bradfield Hall, \\ Ithaca, NY 14843, USA, **Office of the Gene Technology Regulator, Department of Health and Ageing, PO Box 100, Woden ACT 2602, \\ Australia, $\dagger$ Rothamsted Research, Harpenden, Hertfordshire, AL5 2JQ, UK, $\$+$ New Zealand Institute of Crop and Food Resources, Private \\ bag 4704, Christchurch, New Zealand, §§USDA-ARS, North Centre for Soil Conservation Research Laboratory, Morris MN 56267, and \\ $\uparrow$ Department of Agronomy and Horticulture, 201 KCR, University of Nebraska, Lincoln NE 68583, USA
}

Received 28 February 2002

Revised version accepted 31 December 2002

\section{Summary}

To date, several crop : weed competition models have been developed. Developers of the various models were invited to compare model performance using a common data set. The data set consisted of wheat and Lolium rigidum grown in monoculture and mixtures under dryland and irrigated conditions. Results from four crop : weed competition models are presented: ALMANAC, APSIM, CROPSIM and INTERCOM. For all models, deviations between observed and predicted values for monoculture wheat were only slightly lower than for wheat grown in competition with L. rigidum, even though the workshop participants had access to monoculture data while parameterizing models. Much of the error in simulating competition outcome was associated with difficulties in accurately simulating growth of individual species. Relatively simple competition algorithms were capable of accounting for the majority of the competition response. Increasing model complexity did not appear to dramatically improve model accuracy. Comparison of specific competition processes, such as radiation interception, was very difficult since the effects of these processes within each model could not be isolated. Algorithms for competition processes need to be modularised in such a way that exchange, evaluation and comparison across models is facilitated.

Keywords: simulation, Lolium rigidum, Triticum aestivum, crop : weed competition models, common data set.

\section{Introduction}

A number of eco-physiological models of competition between weeds and crops have now been produced. The principal purpose of these models has been to improve our understanding of competition processes (Kropff, 1988; Ryel et al., 1990; Kiniry et al., 1992; Vitta \& Satorre, 1999) by integrating existing knowledge into a logical framework (Chikoye et al., 1996). We learn much by assembling the models and by analysing the reasons for poor fit to data. Once a crop : weed competition model has been developed to a level where there is confidence in its predictions, it can be used in different environments to interpret differences in yield loss due to weeds (Lotz et al., 1990; Lotz et al., 1995; Debaeke et al., 1997; Vitta \& Satorre, 1999), to explore the interactions between crop, weeds, environment and management factors (Chikoye et al., 1996; Lindquist \& Kropff, 1996), and to extrapolate to situations in which there are, so far, no experimental data (Kropff, 1988). Using sensitivity analyses of the models, we can identify plant traits that confer greater competitiveness (Barnes et al., 1990; Lotz et al., 1995; Lindquist \& Kropff, 1996), thus giving direction to crop breeding programmes. 
Some authors consider that process-based competition models can be used to predict yield losses (Orwick et al., 1978; Lotz et al., 1995), although there has been little attempt to validate them for this purpose and most modellers seldom extrapolate far outside their experimental data. There have also been various statements made about the practical significance of eco-physiological competition models. For example, there have been a number of unsubstantiated claims that they can be used to improve weed management (Orwick et al., 1978) and to evaluate weed control programmes (Lotz et al., 1995; Debaeke et al., 1997). Debaeke et al. (1997) propose that they can be used in defining weed control thresholds.

In reality, most of the papers presenting these models merely fit them to a limited set of experimental data for a single site. Although (using a common terminology) the behaviour of the models has been verified, the extent of validation has been considerably limited. If we are to continue to promote the benefits of eco-physiological competition models in research, for any objectives, there is a need to more formally and more rigorously assess their performance.

Simulation models for weed and crop mixtures have mostly arisen as by-products of crop simulation models. Single-species models have been extended to two species by treating each species as a monoculture and then defining rules by which resources are partitioned among the species (e.g. Orwick et al., 1978; Ryel et al., 1990; Kiniry et al., 1992; Kropff \& van Laar, 1993; Weaver et al., 1994; Chikoye et al., 1996; Lundkvist, 1997). Simpler models have also been developed from consideration of how growth rate of one species will be modified by a second species (Cousens, 1988; Vitta \& Satorre, 1999). Each of these models has been developed and parameterized for particular case-studies and the correspondence between predicted and observed values has been explored. However, the data on which the models are 'validated' may often not be independent of the data used in model formulation. Hence, the danger is that they may demonstrate merely that they can predict the input data.

One way of exploring the capabilities of models, and by implication the validity of the processes that have been incorporated, is to parameterize and use these models to predict data that have not been used in model development. Testing this way, under a range of environments, will illustrate the generality of a model (e.g. Matthews et al., 1995; Kiniry et al., 1997). Moreover, comparison of different models on the same case study can further assist evaluation, as it allows us to explore the reasons for failure of some models and the success of others. This has been used to great effect in crop modelling, with comparisons having been made of up to 19 models (Porter et al., 1993; Matthews et al., 1995; Anon, 1996; Kiniry et al., 1997).

The intention of this project was to assess our current understanding of competition by comparing the performances of different crop : weed competition models on species and in an environment that had so far not been used in model development. Through this, we hoped to improve existing models and to set priorities for future research.

\section{Materials and methods}

\section{Field experiment}

Wheat (Triticum aestivum L., cv. Dollarbird) and L. rigidum Gaud. (cv. Guard) were grown in monoculture and mixture on a red-brown earth soil at the Agricultural Research Institute, Wagga Wagga, NSW, Australia $\left(35^{\circ} 10^{\prime} \mathrm{S}, 147^{\circ} 28^{\prime} \mathrm{E}\right)$. Both monoculture and mixture of both species were grown under irrigated and dryland conditions, using a rain shelter and sprinklers.

Both species were sown on 18 May 1998. The wheat was sown mechanically at a rate of $65 \mathrm{~kg} \mathrm{ha}^{-1}$, aiming for 130 plants $\mathrm{m}^{-2}$. The sowing rate of L. rigidum seeds was $20.5 \mathrm{~kg} \mathrm{ha}^{-1}$ aiming for 250 plants $\mathrm{m}^{-2}$. These seeds were mixed with sand to facilitate an even spread, broadcast by hand and then lightly raked into the soil.

The experiment was arranged as a split-plot design with irrigated and dryland conditions (see below) as the main plots and the monocultures, mixtures and harvest times as subplots. The irrigated and dryland conditions were not replicated. Within each main plot, the monocultures and the mixture of both species were replicated five times.

Each monoculture or mixture was grown in plots 7.2 $\mathrm{m}$ in length and eight crop rows wide, with a spacing of $17.8 \mathrm{~cm}$ between rows. At each harvest an area of $0.35 \mathrm{~m}^{2}$ was taken (plants cut at soil level) using only the middle four rows and leaving a $30-\mathrm{cm}$ buffer between subsequent harvests. The first 12 plants from each species were subsampled in a regular manner, after which the rest of the area was harvested in bulk. The subsampled plants were dissected into stem, green and yellow leaf and ear. Tiller number and leaf number on the main stem were counted. The area of green leaf, green stem and green ears was measured using a Delta- $\mathrm{T}^{\circledR}$ leaf area meter (MK2, Burwell, Cambridge, UK). Dry weight of all samples was determined after drying for $48 \mathrm{~h}$ at $90^{\circ} \mathrm{C}$. Harvests were taken at 19,33 , $47,84,101,124,145,173$ and 188 (irrigated only) days after $50 \%$ emergence of the wheat (DAE).

Seedling emergence (day 149 for wheat and 154 for L. rigidum) was recorded in three permanent quadrats 
per plot $(0.3 \mathrm{~m} \times 0.3 \mathrm{~m})$. In order to follow phenological development of both wheat and L. rigidum, eight plants in two replicates were tagged and the Zadoks et al. (1974) decimal code was used. Seed moisture content was measured regularly from fresh and dry weights of 60 (wheat) or 50 (L. rigidum) seeds per plot. The height of the canopy and of the ears of both species was measured regularly by placing a ruler in the crop and taking three measurements.

The amount of intercepted radiation was determined regularly using a ceptometer (AccuPAR, Decagon Devices Inc. USA). On each occasion, light interception was measured three times per plot, perpendicular to the rows.

At sowing, $20 \mathrm{~kg} \mathrm{ha}^{-1}$ phosphorus and $9.5 \mathrm{~kg} \mathrm{ha}^{-1}$ sulphur were applied. To remove nitrogen limitation, equal doses of urea were added on days 198, 209 and 254. The total amount of nitrogen supplied was $120 \mathrm{~kg} \mathrm{ha}^{-1}$ to the dryland plots and $300 \mathrm{~kg} \mathrm{ha}^{-1}$ to the irrigated plots. The differing amounts of nitrogen applied to dryland and irrigated treatments reflect anticipated and expected yield level differences of these two treatments and corresponding differences in nitrogen requirements. Application of equal amounts of nitrogen would have resulted in either a deficiency or an excess of nitrogen in one treatment and not the other, and would have effectively confounded the nitrogen effect. The available amounts of soil mineral nitrogen $\left(\mathrm{NO}_{3}{ }^{-}\right.$and $\left.\mathrm{NH}_{4}{ }^{+}\right)$and phosphorus (Olsen P) prior to sowing were 113 and $27 \mathrm{~kg} \mathrm{ha}^{-1}$ respectively.

For the dryland treatments, the rain shelter was operational from day 170 to day 295. The shelter was deliberately left off the plots on days 198, 209, and 254 to allow rainfall to help infiltration of urea. A total of $15 \mathrm{~mm}$ of rain fell during those 3 days. Over the entire season, the dryland treatments received a total of $74 \mathrm{~mm}$ of rainfall. For the irrigated treatments, irrigation was applied from day 242 onwards. Frequency of application was subjective and increased in mid-late spring. A total of 14 applications were made, totalling $215 \mathrm{~mm}$. Total rainfall plus irrigation during the growing season was $566 \mathrm{~mm}$.

The neutron-scattering technique was used to regularly measure volumetric soil moisture content. One access tube was installed in the centre of each plot. Measurements were performed at $20 \mathrm{~cm}$ intervals between 20 and $120 \mathrm{~cm}$ depth. The neutron probe (Model 503, CPN Corporation, CA, USA) was calibrated for each depth against another machine (Campbell Pacific HP 503) that had previously been calibrated following Greacen \& Hignett (1992). Neutron probe readings were regressed against the average volumetric water content obtained from five intact cores $(75 \mathrm{~mm}$ diameter by $50 \mathrm{~mm}$ long) taken next to the access tube at the different monitoring depths. In order to obtain soil moisture data from the top layer TDR sensors (ThetaProbe soil moisture sensor, Delta-T Devices Ltd, Cambridge, UK) were placed at $10 \mathrm{~cm}$ depth in three of the five replicates.

\section{Simulation exercise and model descriptions}

The crop: weed competition models included in the final simulations were ALMANAC, APSIM, CROPSIM AND INTERCOM. Each modeller was sent the monoculture data and asked to predict the behaviour of the species in mixtures based on their models paramaterized using monoculture data.

An overview of their component structures is given in Table 1 and below.

The modified ALMANAC (Wallace, 1995) model is a process-oriented simulator of a crop : weed community, based on the EPIC crop simulation model (McDonald \& Riha, 1999). Leaf area index (LAI) of a species is a function of (1) the daily change in the heat units required to achieve maximum leaf area, (2) a parameter that sets the maximum potential leaf area index, (3) a daily index of environmental stress (water, soil, or temperature stress) and (4) a maximum leaf area ratio (after 350 accumulated heat units). Height of a species is calculated as a function of species maximum height, the ratio of the maximum canopy height to above-ground dry-matter and a daily index of environmental stress. Intercepted light affects both transpiration and biomass accumulation. The modified ALMANAC partitions intercepted radiation using the ERIN model (Wallace, 1997). Spatial homogeneity (horizontal and vertical) is assumed within the canopy. The Wallace method requires calculation of fractional light interception for two potential extreme conditions. A simple form of linear interpolation is used to calculate fractional light interception for canopies where one species exerts complete dominance over the other. The interpolation equations require a $0-1$ scaling factor, depending on the height of the canopy relative to the total canopy height of all the species. It is assumed that the total light intercepted in a mixed canopy is not dependent on the height of the component species, whereas the intercepted fraction for each species is highly dependent on specific canopy height. The leaf area of each species is assumed to be evenly distributed with height. Root growth of each species in relation to depth is simulated in a manner similar to plant height. Water uptake depends on the potential evapotranspiration of each species and the distribution of the roots in the soil. Water from each soil depth is allocated based on order of species entry by roots into that depth. Light and water competition affect a number of processes including leaf interception of solar radiation, transpiration, leaf area index, height and RUE. The original 
Table 1 Overview of the data requirements and structural components of the four competition models

\begin{tabular}{|c|c|c|c|c|c|}
\hline & & \multicolumn{4}{|l|}{ Model } \\
\hline & & ALMANAC & APSIM & CROPSIM & INTERCOM \\
\hline \multirow[t]{4}{*}{ General } & Time step & Daily & Daily & Daily & Daily \\
\hline & Simulation level & Plant & Plant & Plant & Plant \\
\hline & $\begin{array}{l}\text { Spatial resolution } \\
\text { homogeneous }\end{array}$ & $\sqrt{*}$ & $\sqrt{ }$ & $\sqrt{ }$ & $\sqrt{ }$ \\
\hline & Programming language & Fortran & Fortran & Fortran & Fortran \\
\hline \multirow[t]{9}{*}{ Input requirements } & Daily maximum temperature & $\sqrt{ }$ & $\sqrt{ }$ & $\sqrt{ }$ & $\sqrt{ }$ \\
\hline & Daily minimum temperature & $\sqrt{ }$ & $\sqrt{ }$ & $\sqrt{ }$ & $\sqrt{ }$ \\
\hline & Daily rainfall & $\sqrt{ }$ & $\sqrt{ }$ & $\sqrt{ }$ & $\sqrt{ }$ \\
\hline & Radiation & $\sqrt{ }$ & $\sqrt{ }$ & $\sqrt{ }$ & $\sqrt{ }$ \\
\hline & Longitude and latitude & $\sqrt{ }$ & $\sqrt{ }$ & $\sqrt{ }$ & $\sqrt{ }$ \\
\hline & Soil characteristics & $\sqrt{ }$ & $\sqrt{ }$ & $\sqrt{ }$ & $\sqrt{ }$ \\
\hline & Crop management details & $\sqrt{ }$ & $\sqrt{ }$ & $\sqrt{ }$ & $\sqrt{ }$ \\
\hline & Humidity & & & & $\sqrt{ }$ \\
\hline & Wind run & & & & $\sqrt{ }$ \\
\hline \multirow[t]{2}{*}{ Soil processes } & Soil water balance & $\sqrt{ }$ & $\sqrt{ }$ & $\sqrt{ }$ & $\sqrt{ }$ \\
\hline & Soil nitrogen balance & & $\sqrt{ }$ & $\sqrt{ }$ & \\
\hline \multirow[t]{3}{*}{ Resource competition simulated } & Light competition & $\sqrt{ }$ & $\sqrt{ }$ & $\sqrt{ }$ & $\sqrt{ }$ \\
\hline & Water competition & $\sqrt{ }$ & $\sqrt{ }$ & $\sqrt{ }$ & $\sqrt{ }$ \\
\hline & Nitrogen competition & & $\sqrt{ }$ & $\sqrt{ }$ & \\
\hline \multirow{7}{*}{$\begin{array}{l}\text { Processes directly affected by } \\
\text { water stress at a species level }\end{array}$} & Leaf area development & $\sqrt{ }$ & $\sqrt{ }$ & $\sqrt{ }$ & $\sqrt{ }$ \\
\hline & $\mathrm{RUE} \uparrow /$ photosynthesis & $\sqrt{ }$ & $\sqrt{ }$ & $\sqrt{ }$ & $\sqrt{ }$ \\
\hline & Tillering & & $\sqrt{ }$ & $\sqrt{ }$ & \\
\hline & Development & & $\sqrt{ }$ & $\sqrt{ }$ & \\
\hline & Senescence & & $\sqrt{ }$ & $\sqrt{ }$ & \\
\hline & Partitioning & & $\sqrt{ }$ & $\sqrt{ }$ & $\sqrt{ }$ \\
\hline & Height & $\sqrt{ }$ & $\sqrt{ }$ & $\sqrt{ }$ & $\sqrt{ }$ \\
\hline \multirow{5}{*}{$\begin{array}{l}\text { Processes directly affected by } \\
\text { nitrogen stress at a species level }\end{array}$} & Leaf area development & & $\sqrt{ }$ & $\sqrt{ }$ & \\
\hline & RUE/photosynthesis & & $\sqrt{ }$ & $\sqrt{ }$ & \\
\hline & Tillering & & $\sqrt{ }$ & $\sqrt{ }$ & \\
\hline & Development & & $\sqrt{ }$ & $\sqrt{ }$ & \\
\hline & Senescence & & $\sqrt{ }$ & $\sqrt{ }$ & \\
\hline \multirow{7}{*}{$\begin{array}{l}\text { Processes directly affected by } \\
\text { irradiance stress at a species level }\end{array}$} & Height & & & & $\sqrt{ }$ \\
\hline & Leaf area development & $\sqrt{ }$ & $\sqrt{ }$ & $\sqrt{ }$ & \\
\hline & RUE/photosynthesis & $\sqrt{ }$ & $\sqrt{ }$ & $\sqrt{ }$ & $\sqrt{ }$ \\
\hline & Tillering & & $\sqrt{ }$ & $\sqrt{ }$ & \\
\hline & Development & & $\sqrt{ }$ & $\sqrt{ }$ & \\
\hline & Senescence & & $\sqrt{ }$ & $\sqrt{ }$ & $\sqrt{ }$ \\
\hline & Transpiration & $\sqrt{ }$ & $\sqrt{ }$ & $\sqrt{ }$ & $\sqrt{ }$ \\
\hline
\end{tabular}

$* \sqrt{ }$ indicates that the model simulates the specified process.

$\dagger$ RUE, radiation use efficiency.

model has been applied to Sorghum halepense (L.) Pers., Setaria spp., or Xanthium strumarium (L.) competing with maize (Zea mays L.), soyabean (Glycine max L. Merr.) and wheat (Kiniry et al., 1992), weed competition in wheat (Debaeke et al., 1997) as well as intercropping systems (Kiniry et al., 1995). The modified model has been applied to maize competition with Abutilon theophrasti Medic (McDonald \& Riha, 1999).

In the APSIM model (Carberry et al., 1996; McCown et al., 1996), the number of competing species determines the number of canopy layers. The leaf area of each species is distributed between canopy layers assuming that LAI increases exponentially with plant height. Height growth is a function of stem weight. Leaf area density profile assumes LAI increases exponentially with crop height (but profile shape can be altered). Competition for light affects a range of processes, including biomass accumulation and evapotranspiration. Total absorbed radiation is distributed between species based on differences in leaf area profile, plant height and light extinction coefficients of species. One dimensional root growth is simulated. APSIM predicts below-ground 
competition for resources by simulating water and $\mathrm{N}$-extraction of each species in turn, with the order of extraction alternated between species each day. A number of processes are impacted by water and nitrogen deficit (carbon accumulation, transpiration, phenology, plant survival, grain protein, etc.). The two-species competition version of APSIM has been applied to intercropped systems in Australia consisting of legumes and cereals (Probert et al., 1998).

The two-species version of CROPSIM simulates phenology and growth of competing species. Species interact through competition for light, water and nitrogen. Leaf area growth of each species is determined by (1) leaf area of the first leaf; (2) potential leaf expansion determined by leaf area expansion increment and previous leaf size modified by temperature, water stress and nitrogen stress; and (3) potential tiller leaf expansion related to potential leaf area on main stem. Actual leaf area expansion is determined by potential leaf area expansion of main stem and tillers, assimilate availability and specific leaf area. Total absorbed radiation is distributed between species based on differences in leaf area density profile, plant height and stem area. Species height is simulated as a function of leaf size (prior to stem elongation), stem biomass, stem weight : height ratio, and phenological stage. Root growth is simulated for each species. Actual transpiration of each species is the minimum of potential transpiration and potential soil water uptake by the root system. Nitrogen uptake is based on defined critical concentrations in leaves and shoots. Resource competition affects a range of plant processes including photosynthetic rate and transpiration, leaf area expansion, biomass accumulation and leaf senescence. An earlier version of the CROPSIM competition model was used to simulate photosynthetically active radiation competition between Ambrosia artemisiifolia $\mathrm{L}$. and drybean (Phaseolus vulgaris L.) in Ontario, Canada (Chikoye et al., 1996).

INTERCOM is also based on the simulation of phenology and plant growth. Phenology is controlled by temperature. Species interact through competition for light and water. The model assumes optimum nutrients. Early leaf area growth is temperature controlled, via a relative growth rate of leaf area. Leaf area index $(>0.75)$ is based on dry-matter distribution of leaves multiplied by the specific leaf area. Leaf senescence is temperaturecontrolled and affected by shading above LAI $=5.28$. Light interception is exponential, based on leaf area index, a leaf area density profile, and plant height, with sunlit and shaded leaves separated. Height growth is determined as a logistic function of development stage. Root growth is not modelled, however, a rooting depth for each species is assumed. Water uptake depends the on rooting depths and demands of each species. Potential transpiration is based on potential evapotranspiration, fraction of intercepted radiation and an empirical plant factor (for $\mathrm{C} 3$ or $\mathrm{C} 4$ species). Actual transpiration is the minimum of soil water availability and potential transpiration when soil water content drops below a critical value. This critical value depends on plant type (C3 or $\mathrm{C} 4$ ) and evaporative demand. Light competition affects primarily photosynthetic rate and transpiration. Water competition affects crop photosynthesis and the root : shoot ratio. This model has been used extensively, on a range of crop : weed combinations and in many countries (Kropff \& van Laar, 1993). Examples of INTERCOM simulations of competition include wheat and Avena fatua L. competition for light (Weaver et al., 1994), competition between maize and Echinochloa crusgalli (L.) Beauv. (Kropff et al., 1984), and competition between irrigated rice (Oryza sativa L.) and Echinochloa spp. (Lindquist \& Kropff, 1996).

\section{Statistical analyses}

Field data were analysed using ANOva. Data were $\log _{\mathrm{e}}{ }^{-}$ transformed for weights and leaf areas. Geometric means were calculated for presentation. Where data were transformed, confidence intervals were calculated from the ANOVA and back-transformed for presentation. Deviations between observed and simulated values were calculated from the geometric means. Deviations were defined as differences between simulated and measured values divided by measured values and expressed as a percentage (Mitchell \& Sheehy, 1997).

\section{Results}

\section{Simulation of wheat and L. rigidum growth in monoculture}

Water limitation under the dryland treatment contributed to a final biomass reduction of approximately $47 \%$ in both wheat and L. rigidum (Fig. 1). Maximum leaf area index was reduced by a similar amount (Fig. 2). Height in both wheat and L. rigidum was reduced by lack of water at the end of the season (data not shown).

All four models were able to describe the magnitude of biomass and leaf area response to irrigation for both wheat and L. rigidum (Figs 1 and 2). APSIM, CROPSIM AND ALMANAC were conducted using the same set of parameters for both dryland and irrigated simulations. INTERCOM was run using a separate set of parameters for dryland and irrigated simulations.

While simulated values frequently were within computed confidence intervals, proportional deviations of simulated biomass and leaf area index values from 

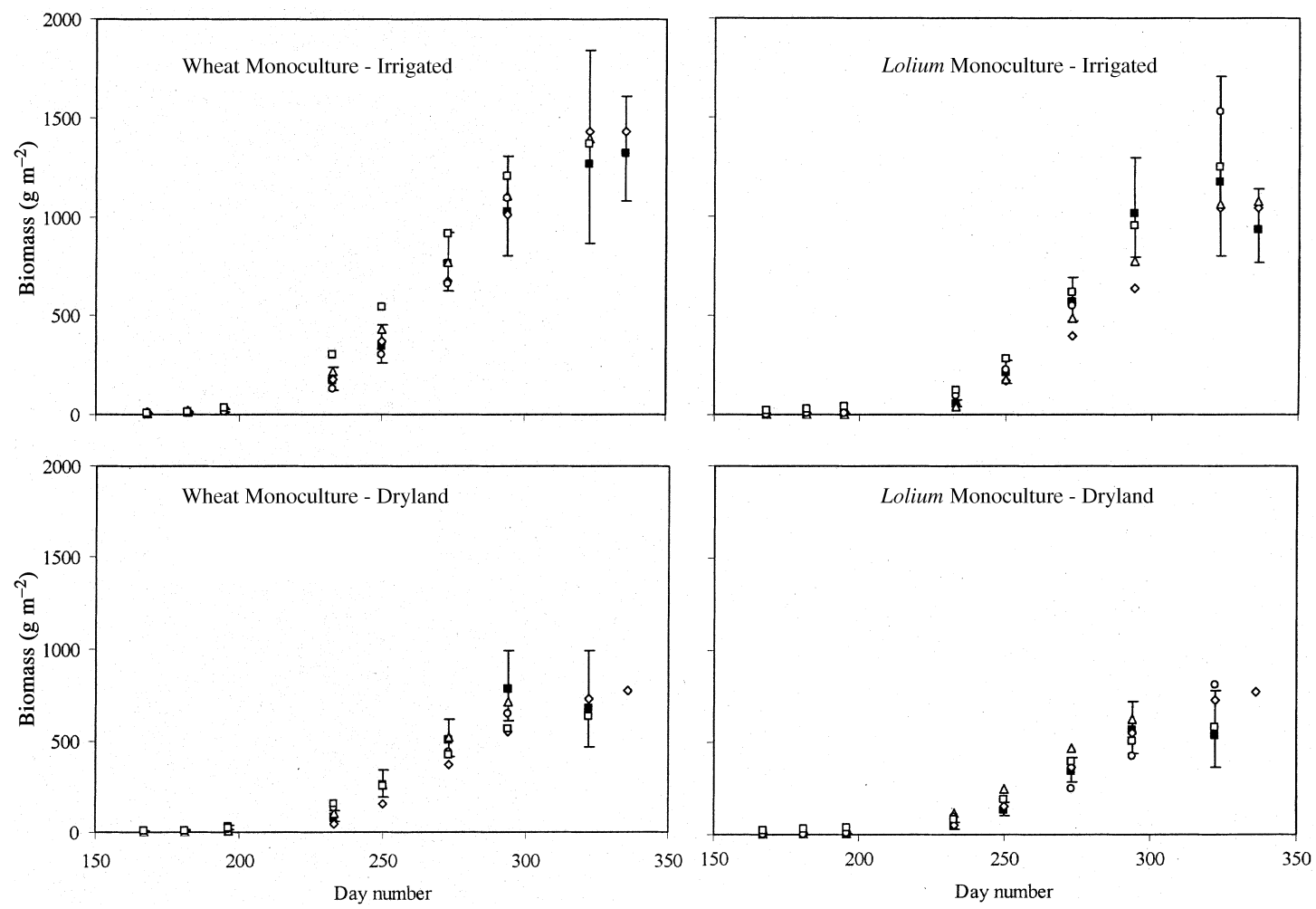

Fig. 1 Measured and simulated biomass of monoculture wheat and L. rigidum under dryland and irrigated conditions, Wagga Wagga, 1998. Measured, $\mathbf{\square}$; ALMANAC, $\diamond$; INTERCOM, $\triangle$ CROPSIM, $\bigcirc$; APSIM, $\square$. Vertical lines equal $95 \%$ confidence interval of the geometric mean.
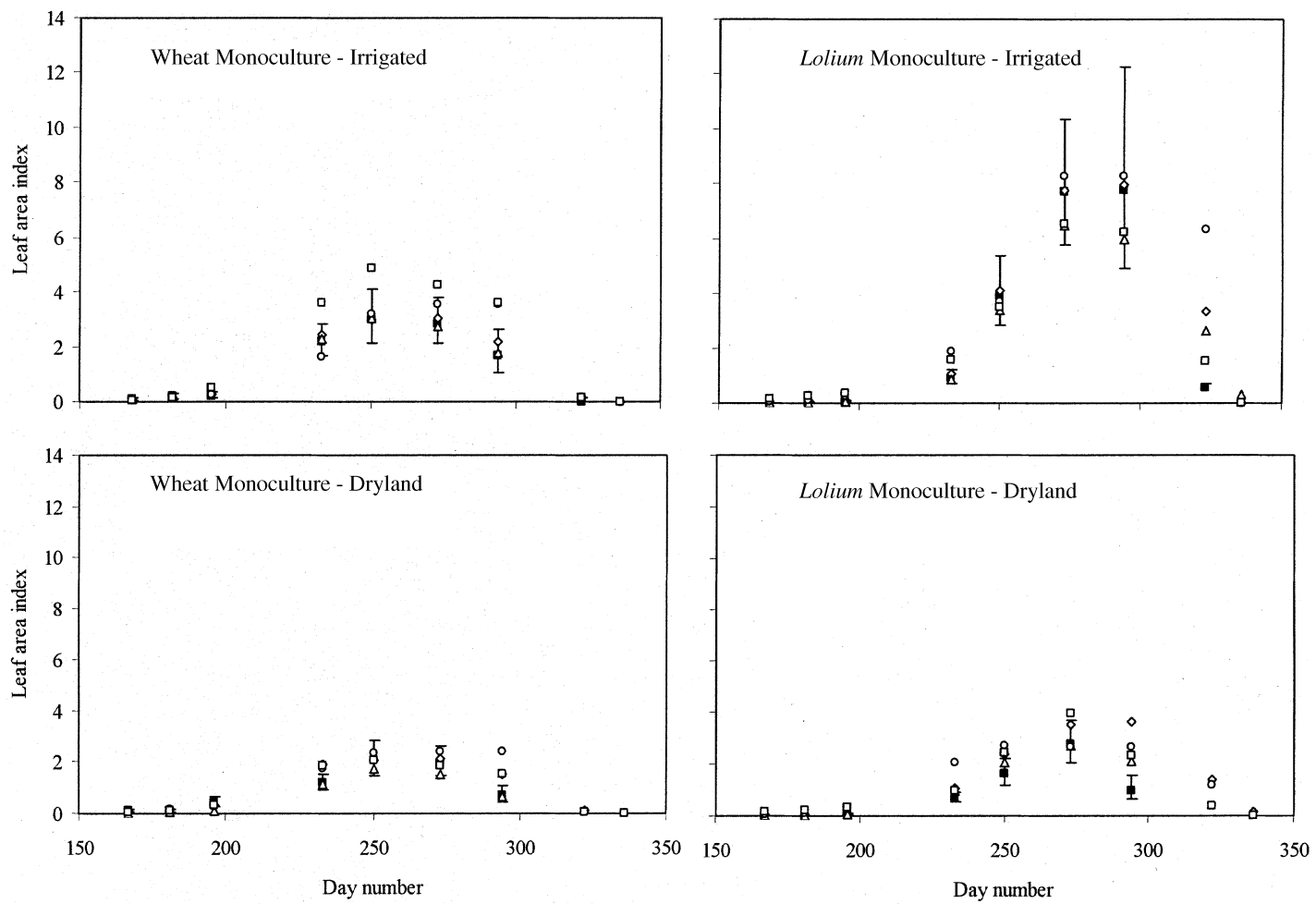

Fig. 2 Measured and simulated leaf area index of monoculture wheat and L. rigidum under dryland and irrigated conditions, Wagga

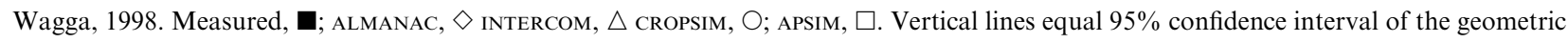
mean. 

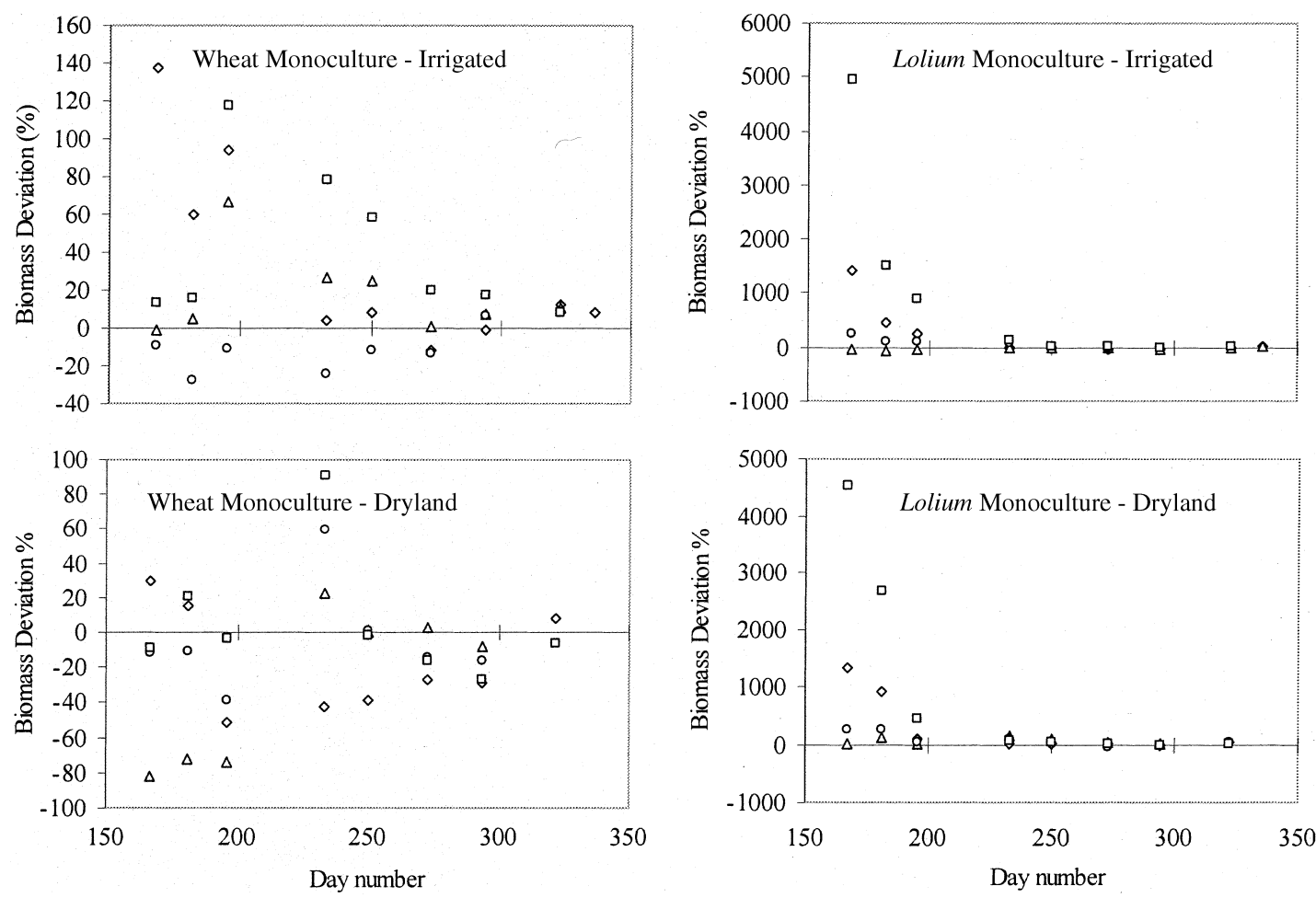

Fig. 3 Deviations of simulated from observed biomass of monoculture wheat and L. rigidum under dryland and irrigated conditions, Wagga Wagga, 1998. ALMANAC, $\diamond$ INTERCOM, $\triangle$ CROPSIM, $\bigcirc$; APSIM, $\square$.

observed means were often large for both wheat and L. rigidum (Figs 3 and 4), particularly at early stages of growth. Deviations for the first two observation dates (19 and 33 DAE) were frequently in excess of $100 \%$. APSIM and ALMANAC tended to have larger deviations at this stage, followed by CROPsim and then INTERCOM.

Average deviations for biomass during the period from day 230 to day 294 were much smaller but still ranged from $6.2 \%$ for irrigated wheat simulations by ALMANAC to $43.3 \%$ for irrigated wheat simulations by APSIM. All models tended to more accurately simulate wheat growth than L. rigidum growth. There did not appear to be a strong correlation between ability to simulate biomass and leaf area index. For example, while Cropsim was able to accurately simulate irrigated wheat biomass for this period, average deviations for leaf area index were $42.9 \%$. INTERCOM most accurately predicted the last leaf area measurement for both wheat treatments, while CROPSIM tended to give the greatest over-predictions of leaf area for wheat and L. rigidum. CROPSIM deviations for leaf area index were larger at day 294 reflecting the fact that leaves senesced faster than predicted.

\section{Wheat and $\mathrm{L}$. rigidum responses to competition}

Wheat and L. rigidum differed in response to competition. Final wheat biomass was reduced by approxi- mately $13 \%$ by competition with $L$. rigidum. Water stress alone, however, caused a $46 \%$ and $18 \%$ reduction under monoculture and mixtures respectively (Figs 1 and 5). Lolium rigidum biomass was affected by competition much more than wheat. Under both dryland and irrigated conditions, L. rigidum biomass was reduced by $81 \%$ when grown in mixture compared with monoculture (Figs 1 and 5). Similarly, wheat leaf area index was affected more strongly by water stress than by competition with L. rigidum, whereas L. rigidum leaf area index was greatly reduced by competition with wheat.

Under competition with wheat, $L$. rigidum responded more strongly with changes to plant morphology, such as specific leaf area and height (data not shown). Lolium rigidum is not necessarily more plastic than wheat. It is the shorter species and subsequently is growing under a different light environment than the wheat. The fact that L. rigidum is much shorter than the wheat undoubtedly explains much of the differential response to growth in mixture. As the plants were adequately provided with nutrients, the competition under irrigated conditions would have been mainly for light.

Wheat height was not affected by competition (data not shown). The ability of wheat to successfully outcompete $L$. rigidum is largely dependent upon the crop gaining early advantage in light interception by faster emergence, developing a taller canopy and greater assimilatory surface, under both irrigated and dryland 

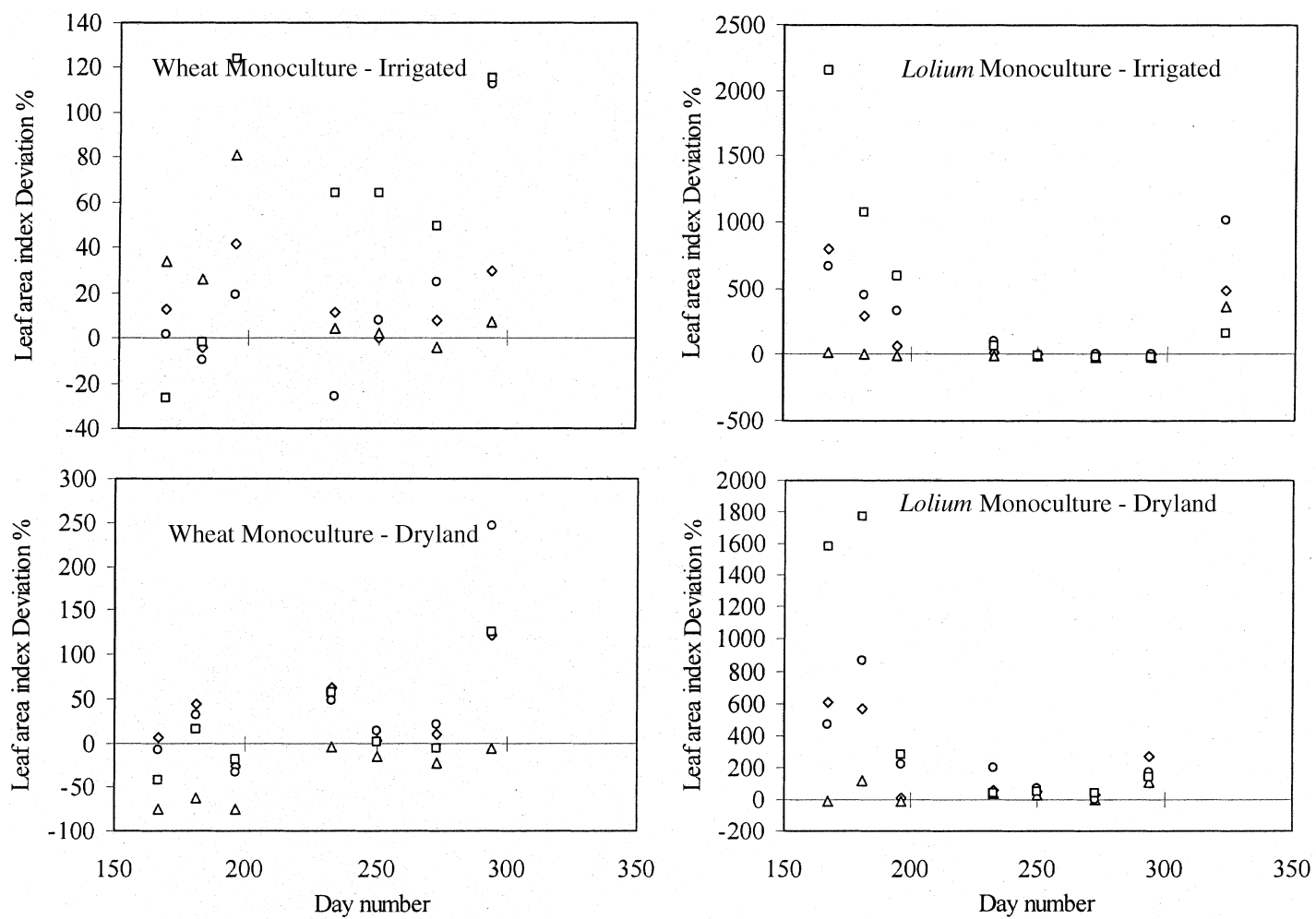

Fig. 4 Deviations of simulated from observed leaf area index of monoculture wheat and L. rigidum under dryland and irrigated conditions, Wagga Wagga, 1998. ALMANAC, $\diamond$ INTERCOM, $\triangle$ CROPSIM, $\bigcirc$; APSIM, $\square$.
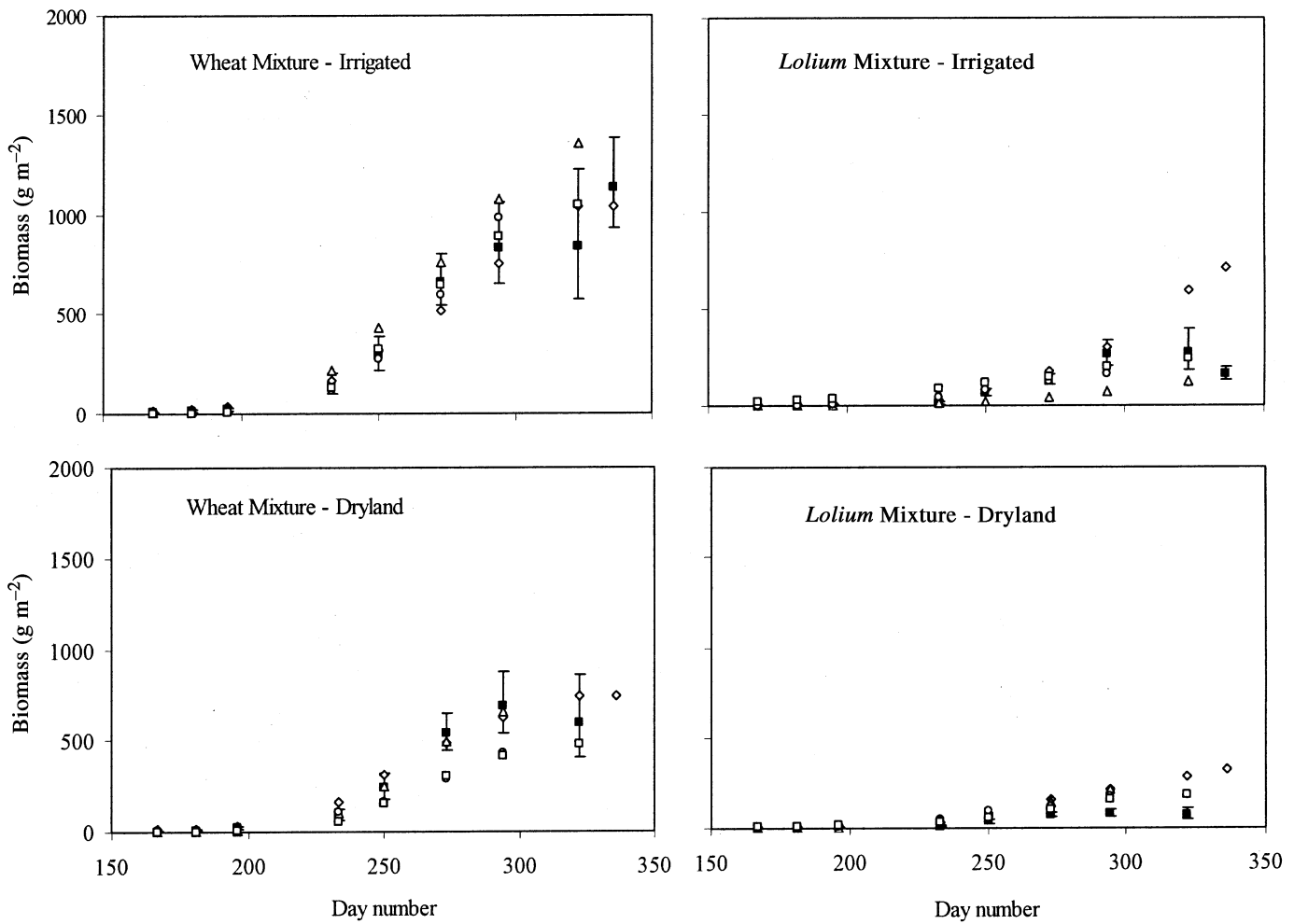

Fig. 5 Measured and simulated biomass of wheat and L. rigidum growing in competition under dryland and irrigated conditions, Wagga

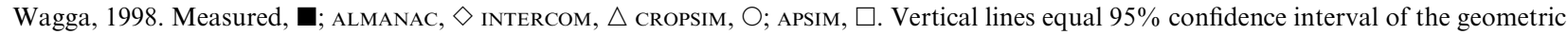
mean. 
treatments. For example, under well watered conditions, irrigated wheat in mixture was able to maximize LAI earlier in the season than L. rigidum, consequently gaining a significant proportion of available light. Although irrigated L. rigidum achieved a considerably higher maximum LAI than wheat in monoculture, the period necessary for canopy closure and light interception to occur was much longer.

A comparison of Figs 1 and 2 with Figs 5 and 6 illustrates that the models paramaterized using monoculture data were generally able to simulate the scale of biomass and leaf area reductions for both wheat and L. rigidum when grown in competition in comparison to monoculture. All models appeared to correctly predict the minimal reductions in wheat biomass and large reductions in L. rigidum biomass. While the magnitude of responses is reasonable, the accuracy of the simulated result is relatively poor, with simulated values for biomass and leaf area index often not falling within computed confidence intervals (Figs 5 and 6).

As with monoculture, deviations between observed and simulated biomass (Fig. 7) and leaf area index (Fig. 8) tend to be larger for the early sampling dates than for later sampling dates. Deviations between observed and simulated biomass for wheat grown under competition were not always higher than for wheat grown in monoculture (Table 2). In some cases, devia- tions were actually smaller. ALMANAC, INTERCOM and CROPSIM were good at predicting wheat biomass in competition with $L$. rigidum under both irrigated and dryland conditions. APSIM performed well under irrigated conditions, but deviations were larger under dryland conditions. Results seem to indicate that wheat in competition with $L$. rigidum can be reasonably simulated using models paramaterized with monoculture data, and using relatively simple competition algorithms for light, water and nitrogen, as in the models in this exercise.

Deviations for leaf area index tended to be higher for wheat grown under competition than for wheat grown in monoculture (Table 2). The effect of this on biomass estimation is minimal, however, particularly for irrigated wheat where high leaf area index was achieved and where over- or underestimation of leaf area would have little effect on percentage light interception.

Both L. rigidum biomass and leaf area index were more poorly simulated under mixture than under monoculture (Figs 5-8, Table 2). Averaged across all models, total dry weight deviations increased by $49.4 \%$ for L. rigidum simulated in mixture with wheat under irrigated conditions and $118.5 \%$ under dryland conditions; deviations for leaf area index increased by $69.4 \%$ and $235.9 \%$ respectively. Lolium rigidum is a shorter species and, as a result, it is more susceptible to light
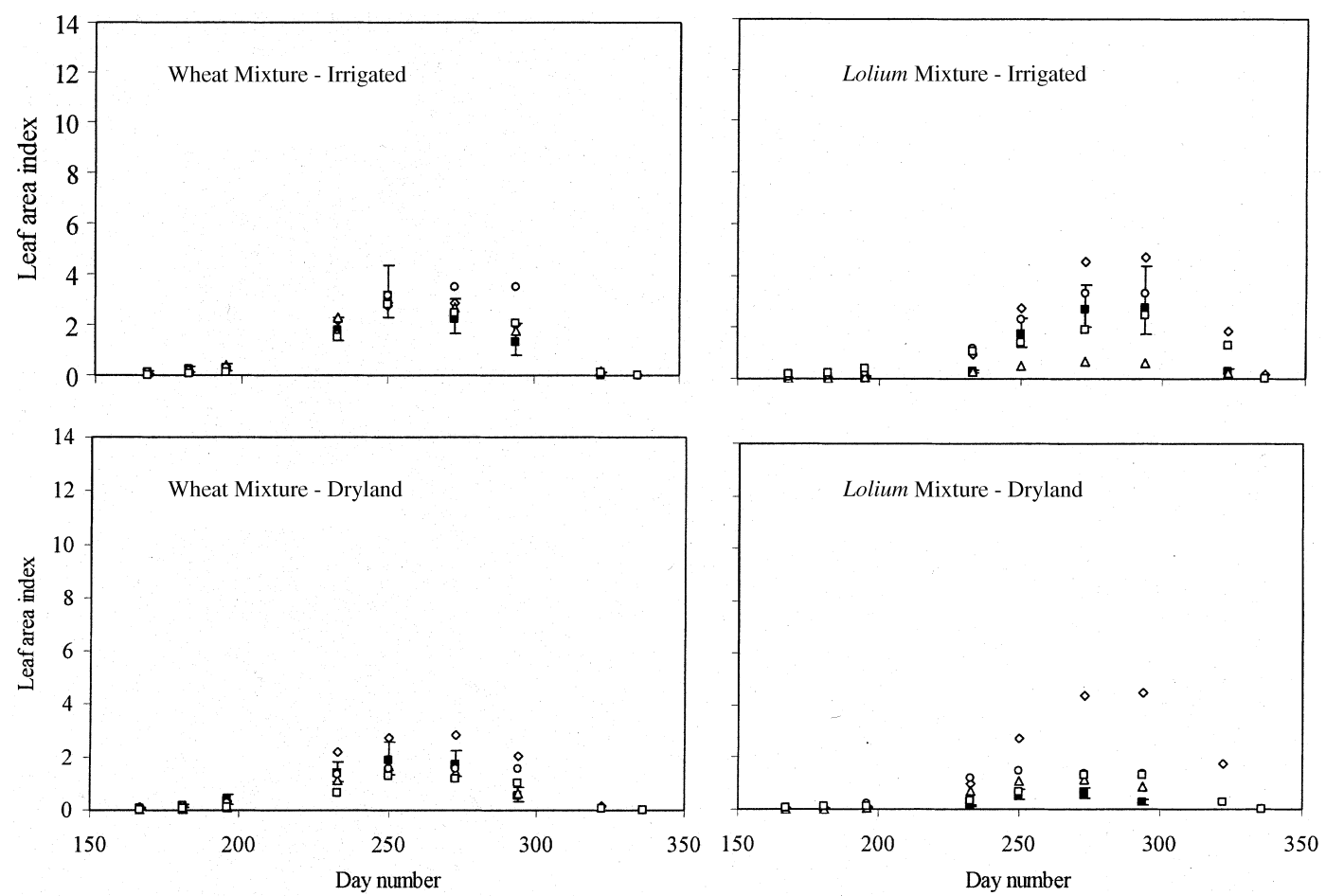

Fig. 6 Measured and simulated leaf area index of wheat and L. rigidum growing in competition under dryland and irrigated conditions, Wagga Wagga, 1998. Measured, $\mathbf{\square}$; ALMANAC, $\diamond$ INTERCOM, $\triangle$ Cropsim, $\bigcirc$; APSIM, $\square$. Vertical lines equal $95 \%$ confidence interval of the geometric mean. 

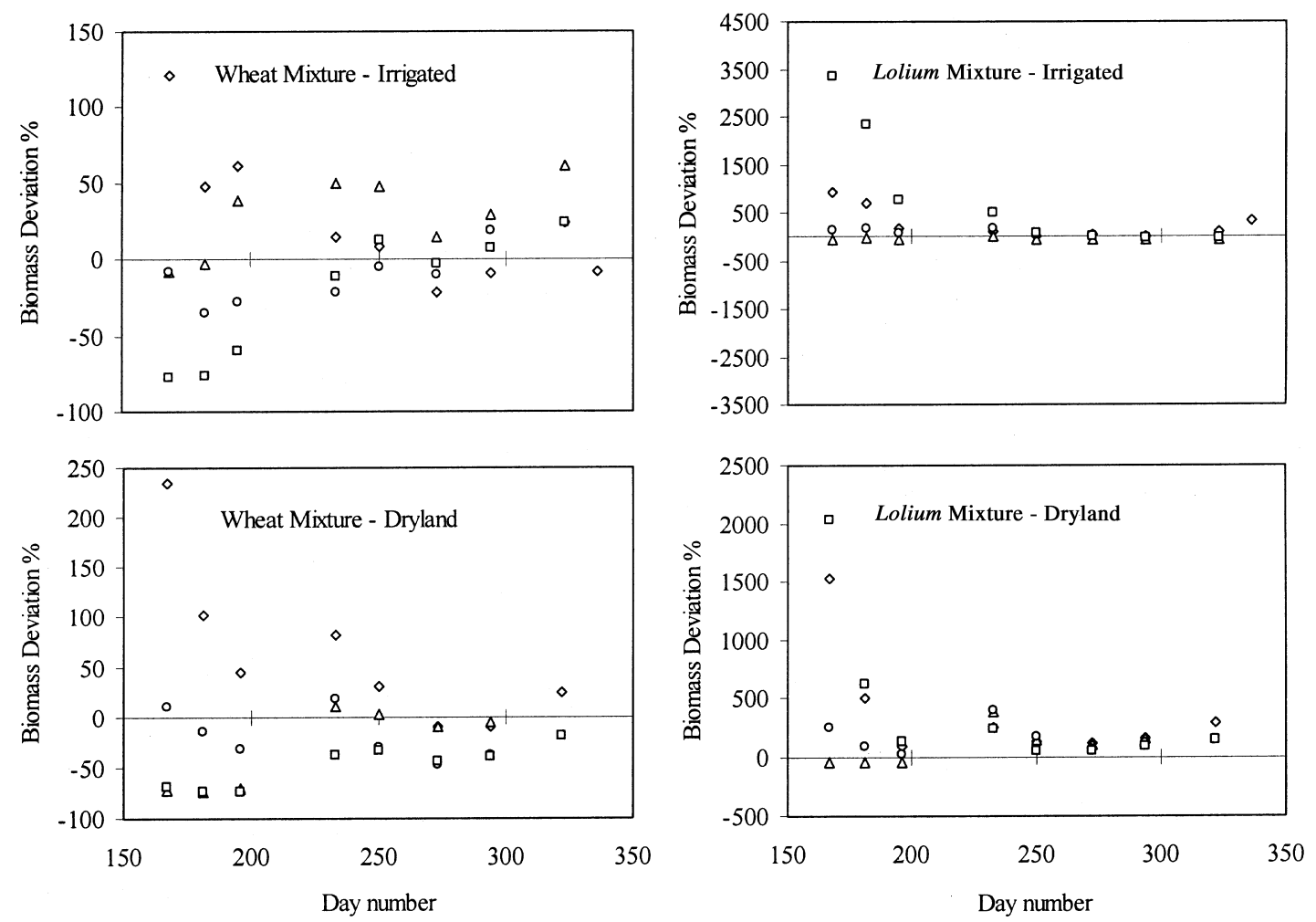

Fig. 7 Deviations of simulated from observed biomass of wheat and L. rigidum growing in competition under dryland and irrigated conditions, Wagga Wagga. ALMANAC, $\diamond$ INTERCOM, $\triangle$ Cropsim, $\bigcirc$; APSIM, $\square$.
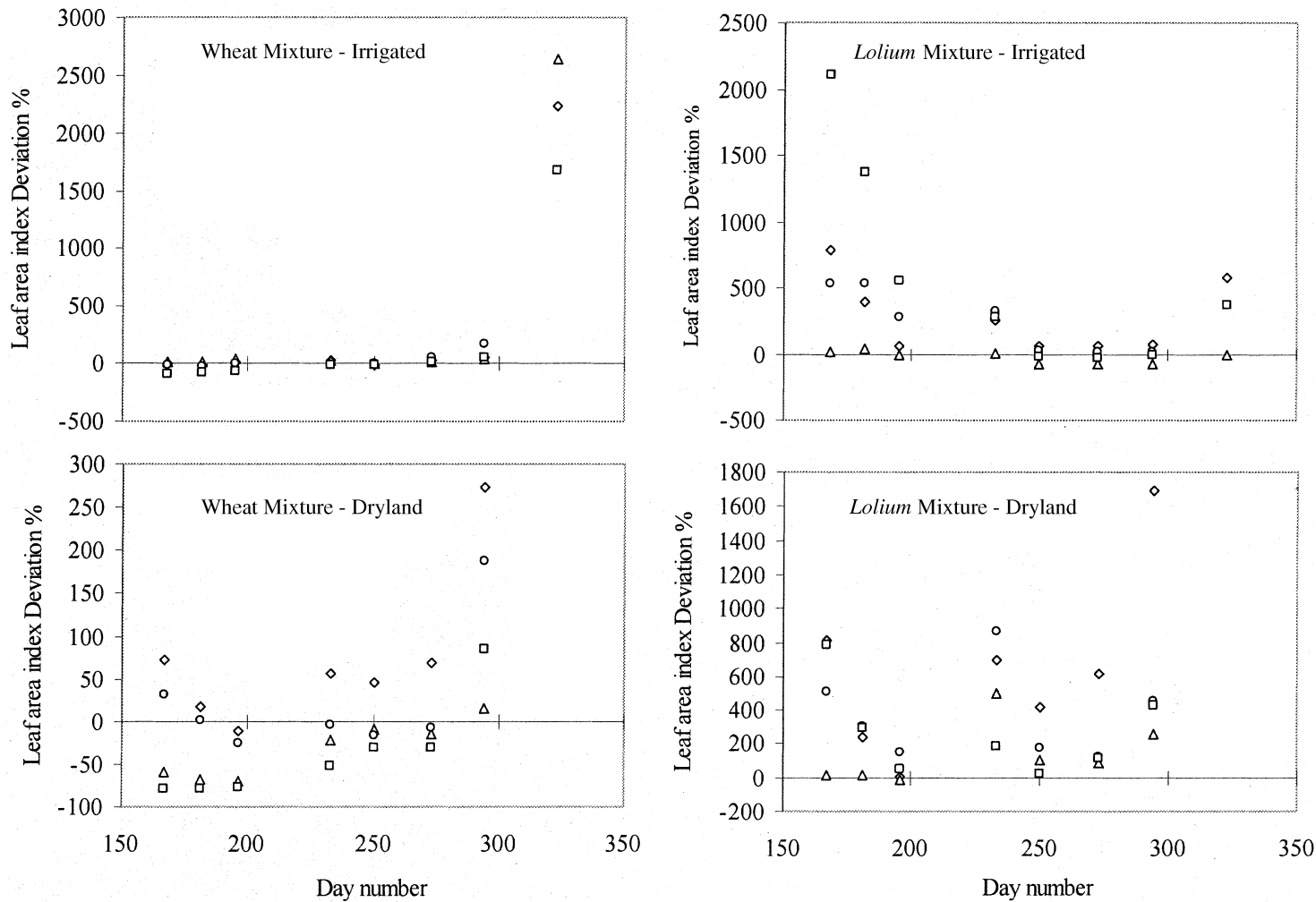

Fig. 8 Deviations of simulated from observed leaf area index of wheat and L. rigidum growing in competition under dryland and irrigated conditions, Wagga Wagga. ALMANAC, $\diamond$ INTERCOM, $\triangle$ CROPSIM, $\bigcirc$; APSIM, $\square$. 
Table 2 Average deviations* of simulated and observed data (day 233-294) for total dry weight and leaf area index for wheat and L. rigidum growing in monocultures and in competition under dryland and irrigated conditions at Wagga Wagga in 1998

\begin{tabular}{|c|c|c|c|c|c|c|c|c|}
\hline & \multicolumn{4}{|c|}{ Total dry weight } & \multicolumn{4}{|c|}{ Leaf area index } \\
\hline & ALMANAC & INTERCOM & CROPSIM & APSIM & ALMANAC & INTERCOM & CROPSIM & APSIM \\
\hline \multicolumn{9}{|l|}{ Wheat } \\
\hline Irrigated - monoculture & 6.2 & 15.2 & 13.9 & 43.3 & 12.3 & 4.4 & 42.9 & 73.0 \\
\hline Irrigated - in competition with L. rigidum & 13.4 & 35.3 & 13.9 & 8.4 & 30.5 & 22.8 & 58.2 & 24.4 \\
\hline Dryland - monoculture & 34.3 & 8.3 & 22.8 & 34.0 & 48.6 & 12.0 & 82.1 & 47.5 \\
\hline Dryland - in competition with L. rigidum & 32.8 & 6.7 & 33.2 & 38.5 & 110.9 & 15.2 & 54.1 & 49.6 \\
\hline \multicolumn{9}{|l|}{ L. rigidum } \\
\hline Irrigated - monoculture & 23.8 & 17.1 & 23.6 & 46.4 & 5.9 & 14.6 & 30.6 & 28.4 \\
\hline Irrigated - in competition with wheat & 44.5 & 50.1 & 63.8 & 150.2 & 113.4 & 58.6 & 100.2 & 84.8 \\
\hline Dryland - monoculture & 7.5 & 72.3 & 51.1 & 35.7 & 98.9 & 46.5 & 108.3 & 67.6 \\
\hline Dryland - in competition with wheat & 160.7 & 192.8 & 182.8 & 104.3 & 431.3 & 239.6 & 405.7 & 188.1 \\
\hline
\end{tabular}

*The direction of the deviation, whether positive or negative, was ignored in calculation of the average.

competition and responds more plastically to the presence of the taller species. In this exercise, models paramaterized with $L$. rigidum monoculture data did not accurately predict $L$. rigidum response to light competition.

\section{Discussion}

Models need to be developed in association with experimental research, drawing on each other in advancing our understanding the system being studied. Therefore, it is to be expected, that even a very good model developed for a particular pair of species under a quite different environment might behave poorly when extrapolated to a new situation. Although poor predictions may result from inadequate algorithms incorporated into the model, they may also reflect the degree of extrapolation and the adequacy of the data set for the particular model. Considerable numbers of measurements were made on the field experiment, but some things were not measured often, if at all, and each modeller had to make assumptions based on little information. Another factor contributing to the different predictions of models is the steps taken in the parameterization process. For example, in a study of pesticide movement in soil, several researchers parameterized the same simple model with the same data set and achieved very different predictions (Boesten, 2000).

Model complexity did not appear to be related to the ability of a model to be fitted to observed monoculture data. CROPSIM, for example, did not provide a better fit than ALMANAC even though it can be characterized as having greater complexity in terms of the processes considered (Table 1). Similarly, a model such as INTERсом that was paramaterized separately for dryland and irrigated conditions, and that was run using observed specific leaf areas, also did not result in noticeably improved simulation accuracy.

A single set of parameters based on monoculture wheat and $L$. rigidum can be used with mechanistic models to simulate wheat and L. rigidum competition under divergent environmental conditions. Four process-driven models, consisting of relatively simple competition routines for irradiance and water, accounted for much of the biomass and leaf area response to competition between these two species. Parameters based on wheat monocultures could be used to simulate wheat response to L. rigidum competition. Lolium rigidum, a shorter and more shallowly rooted species, responds more plastically to competition. As a result, models using parameters based on L. rigidum monoculture did not accurately simulate $L$. rigidum grown in mixture with wheat, indicating that greater model complexity may be required for species that are expected to be less competitive.

Several models exhibited large deviations from field observations early in the season. This can be explained in at least two ways. Firstly, small errors in simulations of emergence date tend to have large effects on accuracy of simulations during early developmental stages (Deen et al. 2001). Secondly, model assessment tends to be done visually during paramaterization and calibration exercises. This tends to skew the modeller towards ensuring fit at later stages where differences between simulated and measured are easier to assess visually. It should be noted that since INTERCOM uses LAI data to estimate the relative growth rate of leaf area (up to an LAI of 0.75), a good fit to the parameterization data set during this period is almost assured.

All models were more effective at simulating L. rigidum biomass and leaf area index under irrigated conditions than under dryland conditions. Lolium rigidum is a less efficient water user with a shallower 
rooting depth (Murphy, 1998). As with light competition, it will be more susceptible to water competition. Water stress affects growth processes through plant morphology (leaf growth and height), light interception and photosynthesis (e.g. Legg et al., 1979; Jamieson et al., 1995). Drought conditions caused considerable reductions in light interception in wheat and L. rigidum by mid-tillering. This was attributed to the reduction in the amount of leaf surface area for assimilation as a result in the decline in leaf area growth and height of wheat and $L$. rigidum under these water-stressed conditions. Most importantly, the reductions to leaf area and height in mixture were considerably greater in L. rigidum than in wheat. The models evaluated in this exercise simulate water balance and root development in a rudimentary, one-dimensional method. As a result, they represent fairly crude approximations of the crop : weed competition system. Errors in simulation of root growth, water balance and distribution, water uptake, or plant response to water deficit, as expected, are greater under water limiting conditions. Although the effects of water deficit on the physiology of crop plants are well documented (Begg \& Turner, 1976), comparatively little is known about the effects of water deficit on weeds and on how physiological processes are affected by interspecific competition (e.g. Munger et al., 1987; Iqbal \& Wright, 1998).

It is believed by many agronomists that L. rigidum competes strongly for nitrogen. This is, at least in part, due to observations that growth of wheat can be reduced by $L$. rigidum, before the plant canopy is fully closed and hence before competition for light would be at its most intense. There are limited data on the response of L. rigidum to nitrogen (Forcella, 1984), but not sufficient to produce a model that would adequately simulate competition for nutrients. In this study, we examined only a situation where nutrients should not have been limiting. However, further empirical research on both water and nitrogen responses would be needed if the models are to be made more realistic, and hence before they could be expected to perform well for the wheat : L. rigidum system in southern Australia.

Most models assume that at least some attributes of plants, such as specific leaf area, leaf distribution and height remain the same whether the species are growing as monocultures or in mixtures with other species. If the competitors are similar in stature, this may be a reasonable assumption. However, if one species is over-topped by the other, it may be expected to exhibit typical physiological responses to shade, such as increased specific leaf area, and alterations in partitioning. Hence, while simple competition algorithms for irradiance, water and nitrogen may account for a large portion of the response of L. rigidum competition, consideration of plastic responses to the availability of these resources may need to be included in models to improve accuracy.

The exercise conducted at this workshop highlights a few key points. First, the primary means of improving mechanistic crop : weed competition model accuracy is through improved simulation of individual species. Much of the error in simulating species in competition is associated with difficulties in accurately simulating individual species, as evidenced in this exercise by the fact that deviations for monoculture wheat were only slightly lower than for wheat grown in mixture. This occurred even though the participants had access to monoculture data while parameterizing models Second, relatively simple competition algorithms are capable of accounting for the majority of the competition response. The models varied as to how plasticity response to competition was simulated. This variation did not appear to dramatically affect model accuracy. Third, it is difficult to compare modelling approaches of specific processes (e.g. radiation competition, height growth, etc.) since the effects of these processes within each model cannot be isolated. Algorithms for competition processes need to be modularised in such a way that exchange, evaluation and comparison across models is facilitated.

Although the project enabled the detailed evaluation of four models (and two other more empirical models not included in this paper), much of the value of an exercise such as this one comes not from the comparisons of predictions, but from the ideas exchanged by the modellers. This outcome is difficult to quantify or to incorporate into a scientific paper, as it relates to future model developments. All participants felt that they had benefited considerably from the exercise, and particularly from the workshop. They designed a further field experiment (now being analysed) to be used for later model validation. Several modellers considered that work was needed on responses of competitors to the modified light environment caused by another dominant species. A group was also formed to continue model development within the GCTE framework.

\section{Acknowledgements}

We thank the Australian Research Council for the research grant to $\mathrm{R}$ Cousens and $\mathrm{M}$ Kropff that supported the generation of the detailed data set for wheat and L. rigidum competition and the international workshop held in Melbourne in November 1999. The Grains Research and Development Corporation and the CRC for Weed Management Systems contributed to the modelling workshop. The CRC for Weed Management Systems also contributed technical support for the field experiment. We also thank the GCTE (Global Change 
and Terrestrial Ecosystems) core research programme of the IGBP (International Geosphere-Biosphere Programme), which has been involved in previous comparisons of crop monoculture models, for actively endorsing the project. Finally, we acknowledge the participation and contribution of D Lemerle and $\mathrm{R}$ Armstrong in the workshop.

\section{References}

Anonymous (1996) GCTE Focus 3 Wheat Network: (1996) Model and Experimental Metadata. Report no. 2. CSIRO, Canberra, Australia.

Barnes PW, Beyschlag W, Ryel R et al. (1990) Plant competition for light analysed with a multispecies canopy model III. Influence of canopy structure in mixtures and monocultures of wheat and wild oats. Oecologia 82, 560-566.

Begg JE \& Turner NC (1976) Crop water deficits. Advances in Agronomy 28, 161-217.

Boesten JJTI (2000) Modeller subjectivity in estimating pesticide parameters for leaching models using the same laboratory data set. Agricultural Water Management 44, 389-409.

Carberry PS, Adiku SGK, McCown RL et al. (1996) Application of the APSIM cropping systems model to intercropping systems. In: Dynamics of Roots and Nitrogen in Cropping Systems of the Semi-Arid Tropics (eds OC Ito, JJ Johansen, K Adu-Gyamfi, et al.), 637-648. Japan International Research Center for Agricultural Sciences, Tsukuba City, Japan.

Chikoye D, Hunt LA \& Swanton CJ (1996) Simulation of competition for photosynthetically active radiation between common ragweed (Ambrosia artemisiifolia) and dry bean (Phaseolus vulgaris). Weed Science 44, 545-554.

Cousens R (1988) A simple simulation model of plant competition and its implications for the design, analysis and interpretation of experiments. In: Proceedings VIII Colloquium International sur La Biologie, Ecologie et Systematique des Mauvaises Herbes, Dijon, France, 695-704.

Debaeke P, Caussanel JP, Kiniry JR et al. (1997) Modelling crop : weed interactions in wheat with ALMANAC. Weed Research 37, 325-341.

Deen W, Hunt T \& Swanton CJ (2001) A mechanistic growth and development model for common ragweed (Ambrosia artemisiifolia). Weed Science 49, 723-731.

ForCElla F (1984) Wheat and ryegrass competition for pulses of mineral nitrogen. Australian Journal of Experimental Agriculture and Animal Husbandry 13, 421-425.

Greacen EL \& HignetT CT (1992) Sources of bias in the field calibration of a neutron meter. Australian Journal of Soil Research 35, 743-764.

IQBAL J \& Wright D (1998) Effects of water deficit and competition on net photosynthesis of spring wheat (Triticum aestivum L.) and two annual weeds (Phalaris minor Retz. \& Chenopodium album L.). Cereal Research Communication 26, 81-88.

Jamieson PD, Martin RJ, Francis GS et al. (1995) Drought effects on biomass production and radiation-use efficiency in barley. Field Crops Research 43, 77-86.
Kiniry JR, Williams JR, Gassman PW et al. (1992) A general, process-oriented model for two competing plant species. Transactions of the American Society of Agricultural Engineers 35, 801-810.

KiniRy JR, Williams JR, Sinoquet H et al. (1995) Simulating intercropping with the ALMANAC Model. In: Proceedings 1994 Ecophysiology of Tropical Intercropping. Guadeloupe, Pointe-à-Pitre, 387-396.

KiniRy JR, Williams JR, VANDERlip RL et al. (1997) Evaluation of two maize models for nine US locations. Agronomy Journal 89, 421-426.

KROPFF MJ (1988) Modelling the effects of weeds on crop production. Weed Research 28, 465-471.

KropfF MJ \& van LAAR HH (1993) Modelling Crop-Weed Interactions. CAB International, Wallingford, UK.

Kropff MJ, Vossen FJH, Spitters CJT \& de Groot W (1984) Competition between a maize crop and a natural population of Echinochioa crus-galli (L). Netherlands Journal of Agricultural Science 32, 324-327.

LegG BJ, DAY W, LAwlor DW et al. (1979) The effect of drought on barley growth models and measurements showing the relative importance of leaf area and photosynthetic rate. Journal of Agricultural Science 92, 703-716.

LindQuist JL \& KROPFF MJ (1996) Applications of an ecophysiological model for irrigated rice (Oryza sativa) Echinochloa competition. Weed Science 44, 52-56.

Lotz LAP, KropfF MJ \& Groeneveld RMW (1990) Modelling weed competition and yield losses to study the effect of omission of herbicides in winter wheat. Netherlands Journal of Agricultural Science 38, 711-718.

Lotz LAP, Wallinga J \& KropfF MJ (1995) Crop-weed interactions: quantification and prediction. In: Ecology and Integrated Farming Systems (eds DM Glen, MP Greaves \& HM Anderson), 31-47. John Wiley \& Sons, Chichester, UK.

LundKvist A (1997) Predicting optimal application time for herbicides from estimated growth rate of weeds. Agricultural Systems 54, 223-242.

Matthews RB, Kropff MJ, Bachelet D et al. (1995) Modeling the Impact of Climate Change on Rice Production in Asia. CAB International, Wallingford, UK.

McCown RL, Hammer GL, Hargreaves JNG et al. (1996) APSIM: a novel software system for model development, model testing, and simulation in agricultural systems research. Agricultural Systems 50, 255-271.

McDonald AJ \& Riha SJ (1999) Model of crop: weed competition applied to maize: Abutilon theophrasti interactions. I. Model description and evaluation. Weed Research 39, 355-369.

Mitchell PL \& Sheehy JE (1997) Comparisons of predictions and observations to assess model performance: a method of empirical evaluation. In: Applications of Systems Approaches at the Field Level (eds MJ Kropff, PS Teng, PK Aggarwal, J Bouma, BAM Bouman, JW Jones \& HH van Laar), 437-451. Kluwer Academic Publishers, London, UK.

Munger PH, Chandler JM \& Cothren JT (1987) Effect of water stress on photosynthetic parameters of soybean (Glycine max) and velvetleaf (Abutilon theophrasti) interspecific competition. Weed Science 35, 15-21.

Murphy C (1998) An ecophysiological analysis of competition for water between cereals and annual ryegrass (Lolium 
rigidum). PhD Thesis, University of Sydney, Sydney, Australia.

Orwick PL, Schreiber MM \& Holt DA (1978) Simulation of foxtail (Setaria viridis var. robusta-alba, Setaria viridis var. robusta-purpurea) growth: the development of SETSIM. Weed Science 26, 691-699.

Porter JR, JAmieson PD \& Wilson DR (1993) Comparison of the wheat simulation models AFRCWHEAT2, CERESwheat and SWHEAT for non-limiting conditions of crop growth. Field Crops Research 33, 131-157.

Probert ME, Carberry PS, McCown RL et al. (1998) Simulation of legume-cereal systems using APSIM. Australian Journal of Agricultural Research 49, 317-327.

Ryel RJ, Barnes PW, Beyschlag W et al. (1990) Plant competition for light analyzed with a multispecies canopy model I. Model development and influence of enhanced
UV-B conditions on photosynthesis in mixed wheat and wild oat canopies. Oecologia 82, 304-310.

Vitta JI \& Satorre EH (1999) Validation of a weed: crop competition model. Weed Research 39, 259-269.

WALlaCe JS (1995) Towards a coupled light partitioning and transpiration model for use in intercrops and agroforestry. In: Ecophysiology of Tropical Intercropping (eds H Sinoquet \& P Cruz). INRA, Paris, France.

WALLACE JS (1997) Evaporation and radiation interception by neighboring plants. QYR Meteorological Society 123, 18851905.

Weaver SE, Kropff MJ \& Cousens R (1994) A simulation model of competition between winter wheat and Avena fatua for light. Annals of Applied Biology 124, 315-331.

Zadoks JC, Chang TT \& Konzak CF (1974) A decimal code for the growth stages of cereals. Weed Research 14, 415-421. 